Canadian Science Publishing

Canadian Journal of Earth Sciences Revue canadienne des sciences de la Terre

\title{
Coastal retreat rates and sediment input in the Minas Basin, Nova Scotia
}

\begin{tabular}{|r|l|}
\hline Journal: & Canadian Journal of Earth Sciences \\
\hline Manuscript ID & cjes-2016-0177.R1 \\
\hline Manuscript Type: & Article \\
\hline Date Submitted by the Author: & $25-$ Nov-2016 \\
\hline Keywote List of Authors: & $\begin{array}{l}\text { Wilson, Erin K.; Dalhousie University, Oceanography } \\
\text { Hill, Paul S.; Dalhousie, Oceanography } \\
\text { van Proosdij, Danika ; Saint Mary's University, Department of Geography } \\
\text { Ruhl, Monique; Dalhousie University, Oceanography }\end{array}$ \\
\hline & Sediment budget, grain size, tidal power, coastal retreat \\
\hline
\end{tabular}




\title{
COASTAL RETREAT RATES AND SEDIMENT INPUT TO THE MINAS BASIN, NOVA SCOTIA
}

\author{
Erin K. Wilson ${ }^{1}$, Paul S. Hill ${ }^{1}$, Danika van Proosdij ${ }^{2}$ and \\ Monique Ruhl ${ }^{1}$ \\ ${ }^{1}$ Department of Oceanography \\ Dalhousie University \\ Halifax, Nova Scotia, B3H 4R2, Canada \\ 2Department of Geography and Environmental Studies \\ Saint Mary's University \\ Halifax, Nova Scotia, B3H 3C3, Canada \\ Corresponding author: erin.k.wilson@dal.ca
}




\begin{abstract}
The Minas Passage in the Bay of Fundy, Nova Scotia is an important site for testing and development of tidal power technologies due to the strength of tidal currents. Understanding sediment processes in this area is essential for determining the impacts that large-scale tidal power extraction would have on the system. Previous estimates of sediment input to the Basin suggest that much more sediment enters the Basin than accumulates within it, so the bottom sediment texture should be in hydrodynamic equilibrium with bottom currents. A recent study, however, showed that sediment texture is generally finer that what is expected based on current speeds. This paper uses Geographic Information Systems methods to provide updated and more highly resolved measurements of the amount of sediment entering the Minas Basin from the dominant source, which is coastal erosion. Volumetric input from coastal erosion is $1.1 \times 10^{6} \mathrm{~m}^{3} \mathrm{a}^{-1}$, which is more than 2 times smaller than previous estimates. This updated value makes input rates comparable to accumulation rates, and agrees with the hypothesis that bottom sediment texture is not in equilibrium with current speeds. Grain size distributions also support the hypothesis that the Minas Basin acts as a sediment trap.
\end{abstract}

ADDITIONAL INDEX WORDS: cliff erosion, tidal power, grain size, sediment budget

\title{
INTRODUCTION
}

The Minas Basin, in the Upper Bay of Fundy, is home to the world's highest tides and a dynamic coastline. Strong tidal currents reaching 8 knots (Parker et al. 2007) have made this area a focus for tidal power development (Li et al. 2013). Extraction of energy by tidal turbines will affect currents (Hasegawa et al. 2011; Wu et al. 2016), and the changes in currents may affect grain size distributions and associated benthic habitats in the Basin. 
The seabed in the Minas Basin is covered by sands and gravels that are mobilized frequently by strong tidal currents (Amos 1978; Li et al. 2015). Amos (1978) argued that these conditions placed the seabed in a state of hydrodynamic equilibrium, in which the sediment size on the seabed is the defined by hydrodynamic stress. In simple terms, larger stresses are associated with larger sediment sizes. Under these conditions, a reduction in seabed stresses from tidal power extraction would cause a reduction in sediment size on the seabed.

Hill and Gelati, (accepted) used a hydrodynamic model of the tides and archived sediment data from the Gulf of Maine and Bay of Fundy to propose, contrary to the Amos (1978) hypothesis, that there is not a direct link between grain size and hydrodynamic stress in the Minas Basin. They observed that seabed grain sizes in the upper Bay of Fundy and Minas Basin were finer than predicted by the model. They argued that the mismatch between modeled and observed grain sizes was caused by oversupply of sediment from cliff erosion. In short, the abundant supply of sand from coastal erosion that is introduced into the upper Bay of Fundy is not exported from the Bay, endowing the seabed with a finer texture than expected given the strong tidal currents. Similar effects of sediment supply on seabed sediment texture have been observed on wave-dominated coasts near rivers (George et al. 2007) and in gravel bedded rivers (Buffington and Montgomery 1999)

An updated sediment budget for the Minas Basin is required to resolve the issue of whether seabed stress or sediment supply determines grain size on the seabed. If seabed stress influences grain size more strongly than supply, then changes in currents associated with tidal power extraction are likely to produce 
changes in seabed sediment texture. Alternatively, if sediment supply dominates and it is not affected by tidal power development, then changes in currents associated with tidal power extraction are not likely to affect seabed sediment texture. The most fundamental requirement of an accurate sediment budget is an updated estimate of the dominant sediment source to the Basin, which is coastline erosion (Amos \& Long 1980).

A sediment budget was completed for the Minas Basin in the 1970's by Amos \& Long (1980). It determined that the dominant input of sediment was from cliff erosion at a rate of $3.09 \times 10^{6} \mathrm{~m}^{3} \mathrm{a}^{-1}$ (Amos \& Long 1980). The other dominant input sediment source is excavation of sediment from the Minas Channel and Minas Passage, which was estimated at $5 \times 10^{9} \mathrm{~m}^{3}$ over the past 3500 years by Shaw et al. (2012). This would result in an average annual input of $1.4 \times 10^{6} \mathrm{~m}^{3} \mathrm{a}^{-1}$ assuming no change with time. This flux is similar to Amos and Long's (1980) estimate of $1.6 \times 10^{6}$ $\mathrm{m}^{3} \mathrm{a}^{-1}$ of transport into the Minas Basin through the Minas Channel and Minas Passage, which was derived from a relatively small set of water column observations. This magnitude of influx is smaller than a model estimate of $3.9 \times 10^{6}$ $\mathrm{m}^{3} \mathrm{a}^{-1}$ based on a 29-day simulation of sediment transport in the Minas Passage and Minas Basin (Wu et al. 2016).

Another sediment source to the Minas Basin is downwearing of shore platforms in front of cliffs. Using shore platform downwearing measurements from Burntcoat Head of $1.25 \mathrm{~mm} \mathrm{a}^{-1}$ (Porter et al. 2010) and an estimated average of 200 
m platform width around the Basin, input from shore platform erosion is estimated to be $8 \times 10^{4} \mathrm{~m}^{3} \mathrm{a}^{-1}$.

These inputs to the Minas Basin either must ultimately be stored in subtidal and intertidal sediment deposits, or they must be exported back out through the Minas Passage and Minas Channel. Over the past 6300 years, an estimated $3.0 \times 10^{9}$ $\mathrm{m}^{3}$ of sediment has accumulated in the subtidal regions (Amos and Joice 1977), giving an average annualized rate of $0.5 \times 10^{6} \mathrm{~m}^{3} \mathrm{a}^{-1}$. Assuming that marshes and intertidal flats accrete at a rate equal to the rate of sea level rise, Shaw et al.'s (2012) estimate of long-term accumulation in intertidal and marsh deposits is equivalent to an average annualized accumulation of $1.5 \times 10^{6} \mathrm{~m}^{3} \mathrm{a}^{-1}$.

The preceding numbers indicate that total inputs to the Minas Basin $(4.6 \mathrm{x}$ $\left.10^{6} \mathrm{~m}^{3} \mathrm{a}^{-1}\right)$ exceed storage in the sediments of the Basin $\left(2.0 \times 10^{6} \mathrm{~m}^{3} \mathrm{a}^{-1}\right)$. This imbalance suggests that the system should approach hydrodynamic equilibrium, due to the need for significant export of sediment from the Minas Basin out to the lower Bay of Fundy through the Minas Passage and Minas Channel. Equilibrium is established because grain sizes that are mobilized more frequently by tidal currents are exported from the Basin preferentially, leaving behind grain sizes in the seabed that are mobilized less frequently.

Invocation of hydrodynamic equilibrium between tidal currents and seabed grain size in the Minas Basin is problematic on several grounds. Hill and Gelati (accepted) showed that the sediment texture in the Bay of Fundy, including the 
Minas Basin, is generally out of equilibrium with the maximum tidal bed shear stress. The expected bed grain size based on maximum near bed flow is larger than what is actually observed. Furthermore, observations (Amos and Long 1980) and models (Li et al. 2015; Wu et al. 2011; Wu et al. 2016) indicate that sediment is imported to, rather than exported from, the Minas Basin.

Imbalance between sediment input to the Minas Basin and sediment storage suggests errors in estimates of storage, inputs or exports. The primary objective of this paper is to use Geographic Information Systems (GIS) methods to measure higher resolution sediment inputs from coastal erosion along the Minas Basin coastline. The second objective is to examine the hypothesis that sediment texture in the Minas Basin is determined by the grain size distribution of the source materials (Gelati 2012; Hill and Gelati accepted) by comparing seabed sediment texture in the Minas Basin with the grain size distribution of material supplied from coastal erosion. By providing updated measurements of the largest sediment source to the Minas Basin system, this study will provide essential data for an updated sediment budget as well as a more highly resolved spatial map of sediment inputs to the system that can be used in future models of sediment texture and transport in the Basin.

\section{METHODS}

\section{Study Site}

The Minas Basin is the southern most branch of the inner Bay of Fundy. It is a semi-enclosed macrotidal embayment that can be divided into four sections: The 
Minas Channel, which connects the Minas Basin to the outer Bay of Fundy, the Central Minas Basin, extending between Cape Split and Economy Point, the Southern Bight, the southern most part of the Basin, and Cobequid Bay to the east. This study

focuses on the latter three (Figure 1). These three sections together create an almost triangular bay with a length of $62 \mathrm{~km}$ and maximum width of $26 \mathrm{~km}$ (Parker et al. 2007). The mean tidal range in the Basin is $12 \mathrm{~m}$ with a maximum of $16.3 \mathrm{~m}$ at Burntcoat Head (Knight 1972). These high tides occur because the natural period of the oscillation of the Bay of Fundy nearly matches the tidal period, resulting in resonance (Garrett 1972).

The Minas Basin is surrounded along 79\% of the coastline by steep cliffs that are composed mostly of unstable Triassic sandstone (Amos \& Long 1980). The highest steep cliffs lie along the north shore of the Central Basin between Parrsboro and Five Islands, as well as along Cape Split. The rest of the shore of the Central Basin and the southern shore of Cobequid Bay are dominated by lower steep cliffs. The remainder of the coastline comprises dykes, bluffs and salt marshes.

\section{Determining Erosion Rate and Sediment Input}

\section{General Approach}

Previous studies of coastal erosion in the Minas Basin were limited in the resolution that could be achieved (Amos and Joice 1977). Although aerial photographs were available, calculated erosion rates and volumetric inputs along the coastline were computed at discrete points. Values from those widely spaced 
discrete sites were used to represent long stretches of coastline over long periods of time. The spatial and temporal scaling problems potentially degraded the accuracy of the estimated inputs of sediment by coastal erosion. With Geographic Information Systems (GIS), more accurate and higher resolution measurements are possible. The software package ArcGIS 10.1 was used for this analysis.

Time periods and sections were determined by the availability of digitized aerial photographs of the coastline. The earliest available digitized photos of most of the coastline were taken in 1964. The entire coastline was photographed in the early 1990s. The base satellite maps in ArcGIS were used as the most recent coastline in 2013 . The time periods are stated throughout as 1964 - early 1990 s and early 1990s to 2013. Specific years used for each section are shown in Table 1 . The coastline was divided into 6 sections (Figure 1) based on where and when photographs were available. Each section was analyzed separately for data management purposes and then compiled to derive erosion rates and volumetric sediment input for the entire system.

Photographs were georeferenced to the base satellite imagery (2013) with the georeferencing toolbar in ArcMap using control points at road intersections and buildings. Overall errors associated with georeferencing, calculated using the RMSE, ranged from 0.5 to $5 \mathrm{~m}$, with larger errors occurring in photos dominated by water or mudflats. The base imagery was projected using the UTM zone 20 coordinate 
system and the NAD83 WGS84 datum. Stereophotography techniques were used to minimize photo distortion.

\section{Erosion Rates}

Polylines of the coastline were generated using on-screen digitization. To ensure changes between time periods were measured accurately, the coastline was always traced along the top edge of cliffs and the top edge of dykes or bluffs where cliffs were not present. Top edge of cliffs and dykes were determined visually.

The Euclidean Distance tool in the Spatial Analyst toolbar was used to create a distance file from the digitized coastlines (ESRI ${ }^{\circledR}$ White Paper 2001). This tool measures orthogonal distance continuously along a line out to a set distance (100 m). This tool was used on the 1964 coastlines as well as the early 1990 s coastline. These distance files were used when measuring the distance from the 1964 coastline to the early 1990 s coastline and to the 2013 coastline, as well as from the early 1990s coastline to the 2013 coastline. Erosion rates were measured for each time period as well as the overall study period. The process was the same for each section, so section 1 is used below as an example to describe the methods.

The 2013 and 1995 coastlines were interpolated using the distance files created above. The interpolate shape tool in the 3D Analyst toolbox was used. The input feature was the coastline of the most recent time period and the input surface was the distance file from the oldest coastline. For example, to measure the erosion 
distance from 1995 to 2013 , the 2013 coastline and the 1995 distance file were used. The output file was a line with "distance eroded" values that was used in the 3D Analyst toolbox to create a profile graph of the distance eroded along the line for each section.

To compare erosion values between sections, erosion rate $\left(\mathrm{m} \mathrm{a}^{-1}\right)$ was calculated in the attribute table. Analysis of variance (ANOVA) was completed using Minitab to test for significant difference in erosion rates between the 6 sections using overall rates (1964 - 2013). A paired-t test was completed in Minitab to look for significant changes in erosion rates between time periods for the entire coastline as well as within each section. A 95\% confidence interval ( $\alpha=0.05)$ was used for all statistical tests.

\section{Volumetric Input}

Volume of sediment eroded was calculated as the area eroded over the study period multiplied by cliff elevation. A digital elevation model (DEM) was created from the NSTDB 1:10 000 topographic maps using the topo to raster tool, as LiDAR data were not available for this study. The original topographic data have a horizontal resolution of $5 \mathrm{~m}$. The interpolated DEM has a horizontal resolution of 1 $\mathrm{m}$.

To calculate the area of land eroded between time periods, coastlines from the different time periods were connected at the end of each section and merged. 
The connected polyline was converted to polygons representing the area of coastline lost using the feature to polygon tool. The areas of the polygons were calculated by using the calculate geometry option in the field calculator. This operation produced a new field in the attribute table with the area of each polygon. The sum of the areas of all of the polygons created was calculated by using the sum of the field in the attribute table, giving the total area eroded for that section.

Area polygons were multiplied by the elevation data to calculate the total volume of sediment eroded. Vector polygons were converted to raster files with cell sizes matching the DEM using the convert to raster tool. The extract by mask tool was used to extract the DEM for the shape of each polygon or eroded area. The input raster is the DEM, and the input feature is the polygon raster files.

Volumes of sediment for each polygon were calculated using the surface volume tool in the 3D analyst toolbox. For each of the DEM polygons, the volume above the beach elevation value was calculated, which helped to account for the fact that the bottom eroded area was not always at sea level. An assumption was made that the bases of eroding shorelines were flat where in some cases the bases were sloped. This assumption results in slight overestimation in the volume measurements. Based on a $1^{\circ}$ beach slope and $10 \mathrm{~m}$ cliff height, the overestimation is less than $1 \%$, and this value decreases with higher cliff elevations. Volume input rates were determined for both time periods in each section, as well as overall. The 
same statistical tests were carried out for these values as were completed for erosion rates.

\section{Grain Size Analysis}

A total of 92 sediment samples were collected from 39 sites along the coastline of the Minas Basin in summer 2014 and 2015 from bedrock (56), unconsolidated beach sediments (29), and till (7) to be used from grain size distribution analysis. The Wolfville formation, composed of Triassic sandstone, surrounds most of the Basin and was sampled on both the north and south shore of the Central Basin and Cobequid Bay (Figure 1). The Horton Bluff formation, composed of sandstone as well as siltstone and shale, was sampled at the mouth of the Avon River. The North Mountain formation, a basalt formation, is exposed at Cape Split and was sampled near Blomidon (Figure 1).Samples from unconsolidated material were collected with a trowel. A hammer was used to sample bedrock. Shoreline samples were taken at the base of cliffs and from till deposits that were safely accessible from shore. Beach samples were taken $15 \mathrm{~m}$ from cliff base and no beach profiles were taken.

Approximately $150 \mathrm{~g}$ was taken from each sample and dried in an oven for at least 24 hours. Dried samples were weighed, crushed, and washed through a $63 \mu \mathrm{m}$ sieve. After wet-sieving, samples were dried and re-weighed to determine the proportion of sediments less than $63 \mu \mathrm{m}$. The remaining sediment was put through 
a WS Tyler standard sieve set ranging from $2 \mathrm{~mm}$ to $63 \mu \mathrm{m}$ and shaken for 20 minutes. Fraction retained on each sieve was recorded. The data obtained from sieving were used to create graphical representations of weight distribution of samples and to compare with the distribution for seabed samples.

Seabed samples were collected by Bedford Institute of Oceanography (BIO) scientists in June 2013. Nearshore (92) samples were collected using Van Veen and Ekman grabs and deep water samples (69) were collected using a Video Grab (Schwinghamer et al. 1996) and slo-corer (Law et al. 2008). Sampling locations were based on locations of other BIO equipment as well as on the goal of obtaining a broad geographic representation of sediment sizes in the Basin (Figure 1). Samples were dried, crushed, and sieved at BIO.

\section{RESULTS}

\section{Retreat Rates}

Over the entire study period (1964 - 2013), retreat rates of the coastline of the Minas Basin varied from $0 \mathrm{~m} \mathrm{a}^{-1}$ to $1.4 \mathrm{~m} \mathrm{a}^{-1}$. The highest retreat rates were found between Five Islands and Parrsboro, the north western shore of Cobequid Bay, to the west of Walton, and near Selma and Blomindon (Figure 2). Overall retreat rates were highest in section 1 with an average of $0.5 \mathrm{~m} \mathrm{a}^{-1}$. Section 3 and 6 showed the lowest retreat rates with an average of $0.34 \mathrm{~m} \mathrm{a}^{-1}$ and $0.35 \mathrm{~m} \mathrm{a}^{-1}$ (Figure 2). Section 1 had retreat rates significantly higher $(\mathrm{p}<0.05)$ than sections $3,4,5$ and 6 . Retreat 
rates in section 2 were significantly higher than sections 3 and 6 . The mean retreat rate was $0.42 \mathrm{~m} \mathrm{a}^{-1}$ for the entire coastline.

A paired-t test indicates that retreat rates were significantly larger $(\mathrm{p}=$ 0.001) in time period 2 (early 1990s - 2013) than they were in time period 1 (1964 - early 1990s) (Figure 3). Time period 1 had a mean retreat rate of $0.39 \mathrm{~m} \mathrm{a}^{-1}$ (S.D. = $0.25 \mathrm{~m} \mathrm{a}^{-1}$ ), where time period $2 \mathrm{had}$ a mean retreat rate of $0.48 \mathrm{~m} \mathrm{a}^{-1}$ (S.D. $=0.30 \mathrm{~m}$ $\left.\mathrm{a}^{-1}\right)$. Retreat rates were higher in time period $2(\mathrm{p}<0.05)$ in sections $1-5$ (Figure 3$)$, with section 5 showing a smaller increase. There was a significant decrease $(\mathrm{p}<$ 0.001 ) from $0.46 \mathrm{~m} \mathrm{a}^{-1}$ in time period 1 to $0.27 \mathrm{~m} \mathrm{a}^{-1}$ in time period 2 in section 6 . The largest increases were between Five Islands and Parrsboro, along most of the Cobequid Bay coastline, and near Walton (Figure 3). The greatest increase in retreat rate was in section 3 where the mean rate increased from $0.23 \mathrm{~m} \mathrm{a}^{-1}$ to $0.49 \mathrm{~m} \mathrm{a}^{-1}$.

\section{Volume Input}

Volume input rates over the entire study period along the coast of the Minas Basin ranged from $0 \mathrm{~m}^{3} \mathrm{a}^{-1} \mathrm{~m}^{-1}$ to $75.6 \mathrm{~m}^{3} \mathrm{a}^{-1} \mathrm{~m}^{-1}$. The largest volume inputs were between Five Islands and Parrsboro and near Blomidon. This area also had some of the highest erosion rates and highest coastline elevations. Overall volumetric inputs were significantly higher $(\mathrm{p}<0.001)$ in section 1 , with an average of $11.2 \mathrm{~m}^{3} \mathrm{a}^{-1} \mathrm{~m}^{-1}$, than in any other section,. Volumetric input rates were lowest in section 6 with a value of $3.4 \mathrm{~m}^{3} \mathrm{a}^{-1} \mathrm{~m}^{-1}$. This value was only significantly lower $(\mathrm{p}<0.001)$ than input 
rates from section 1 and section 2 . The mean volumetric input rate for the entire Minas coastline was $5.7 \mathrm{~m}^{3} \mathrm{a}^{-1} \mathrm{~m}^{-1}$.

The volumetric input rates were higher in time period 2 (early 1990s - 2013) than they were in time period 1 (1964 - early 1990s) $(\mathrm{p}<0.001)$ in sections $1-5$ (Figure 5). Volumetric input rates were lower in time period 2 in section 6 (p < 0.001). For the overall basin, time period 1 had a mean input rate of $4.5 \mathrm{~m}^{3} \mathrm{a}^{-1} \mathrm{~m}^{-1}$, and time period 2 had a mean input rate of $6.3 \mathrm{~m}^{3} \mathrm{a}^{-1} \mathrm{~m}^{-1}$. The largest increases were in sections 1 and 3, although the volume input from section 1 was nearly 4 times greater than the input from section 3 . The increase in volumetric input in section 3 was associated with the increase in retreat rate. The increase in retreat rate in section 1 was not as large, but the cliff elevations were higher, leading to a larger change in volumetric input. The total amount of sediment entering the Basin per year increased from $9.0 \times 10^{5} \mathrm{~m}^{3} \mathrm{a}^{-1}$ in time period 1 to $1.3 \times 10^{6} \mathrm{~m}^{3} \mathrm{a}^{-1}$ in time period 2. The overall mean input rate for the entire study period was $1.1 \times 10^{6} \mathrm{~m}^{3} \mathrm{a}^{-1}$.

\section{Grain Size Distribution}

Sand size grains represented the majority of the sediment mass in tills (T), cliffs (C), and beaches (B) at the sampling sites that fringe the Minas Basin (Figure 6a). The Wolfville formation sandstone that surrounds most of the Basin is the exposed bedrock present at most of the sampling sites. The Horton Bluff formation, composed of sandstone as well as siltstone and shale, was present at two sample 
sites near the mouth of the Avon River and at Cheverie (Figure 1). The Blomidon Formation, made up of shale, claystone, and siltstone was present at the sample sites near Blomidon.

Sand also dominated the subtidal nearshore (NS) and deeper water (DW) deposits (Figure 6a). Silts and clays decreased offshore with a maximum in the tills. Gravel had a maximum in deep water. Proportions of different sand size classes (Table 2) showed the same pattern of offshore coarsening (Figure 6b). Coarse and medium sands dominated the deep-water samples. Fine sand was the dominant fraction in nearshore samples and in cliffs, beaches, and till. The average grain size of seabed samples was medium sand compared to an average of fine sand seen in land samples (Table 3).

\section{DISCUSSION}

\section{Retreat Rates}

Significantly higher retreat rates were observed in time period 1 compared to time period 2. Causes of increase in retreat rates are unclear. Generally, long term changes in retreat rates have been linked to increasing sea level (Brooks and Spencer 2012). This effect has not yet been examined in the Minas Basin. Overall, retreat rates did not correlate with geological and environmental factors such as bedrock geology, surficial geology, terrain and drainage. Higher retreat rates occurred in areas that had higher cliff elevations. This observation is consistent with others that showed that steep cliffed coastlines often erode due to failures triggered by other events such as undercutting by waves (Young et al. 2009). Also, as 
undercutting at the base of a cliff occurs, mass movement by slumps and rock falls becomes more common (Emery and Kuhn 1982). However, Trenhaile (1999) suggests that there is an inverse relationship between platform width and cliff height because with higher cliffs, more material is provided by rockfalls, and this material can protect the base of the cliff from further undercutting if it remains in place at the base. If eroded material is suspended, or there is a beach present, suspended sediment can act as an abrasive tool and aid in the erosion process (Bird 1969; Pye and Blott 2015; Robinson 1977).

The friable nature of the Triassic sandstone cliffs is often cited as the reason for high retreat rates in the Minas Basin (Amos and Long 1980; Desplanque and Mossman 2004), however, physical hardness is not solely what determines rock resistance as strike, dip, joint density and environmental factors can all play a role (Trenhaile 1999). Variations in erosion rates along the Minas Basin coastline highlight more complex processes at work.

Sea level rise due to climate change is also a threat to highly erodible cliffs (Lee 2008). Brooks and Spencer (2012) found that soft rock cliffs with high erosion rates along the Suffolk Coast, UK respond to sea level raise similar to the SCAPE approximation (Ashton et al. 2011) where the change in retreat rate is proportional to the square root of the change in sea level. However, all predictions of shoreline response rely heavily on accurate measurements of baseline retreat (Brooks and Spencer 2012).

To predict retreat rates in the future more accurately, other factors that can control erosion processes will need to be assessed. Wave propagation models and 
cliff inundation models have not been created for the Minas Basin. Cliff inundation and wave propagation as well as correlation with changes in sea level may give better insight to causes of higher retreat rates and changes in those rates over time. Episodic erosion events also will need to be linked mechanistically to longer term average erosion rates (Dunn et al. 2000).

To explore the observed increase in retreat rates in this study as indicative of a possible trend, the temporal resolution of measurements needs to be improved. Temporal resolution could be increased by focusing on smaller lengths of coast for which aerial photographs are available for a greater number of years.

\section{Sediment Input}

Amos and Long (1980) reported overall inputs of $3.09 \times 10^{6} \mathrm{~m}^{3} \mathrm{a}^{-1}( \pm 0.93 \mathrm{x}$ $10^{6} \mathrm{~m}^{3} \mathrm{a}^{-1}$ ) using data from 1939 to 1964 . This value is approximately three times greater than the $9.0 \times 10^{5} \mathrm{~m}^{3} \mathrm{a}^{-1}$ and $1.3 \times 10^{6} \mathrm{~m}^{3} \mathrm{a}^{-1}$ for time periods 1 (1964 - early 1990s) and 2 (early 1990s - 2013) respectively from the current study. The number from Amos and Long (1980) includes volume input from a section along Cape Split $\left(0.68 \times 10^{6} \mathrm{~m}^{3} \mathrm{a}^{-1}\right)$, which was not included in the current study due to the degree of distortion in the photographs. Amos and Long (1980) did not measure erosion rates around Cape Split. Their sediment input value was calculated using elevation from the site and an erosion rate extrapolated from a section further south along the coast of the Southern Bight. Subtracting the sediment input from Cape Split still leaves Amos and Long's (1980) value more than 2 times larger than the updated input. Another method of retreat rate measurement is needed to estimate sediment 
input from the Cape Split section of coastline.

The updated average sediment input value from coastal erosion of $1.1 \times 10^{6}$ $\mathrm{m}^{3} \mathrm{a}^{-1}$. An estimated $1.4 \times 10^{6} \mathrm{~m}^{3}$ of sediment is excavated from the floor of the Minas Channel and Minas Passage each year and transported in the Basin (Shaw et al. 2012) and $8 \times 10^{4} \mathrm{~m}^{3} \mathrm{a}^{-1}$ is introduced by downwearing of platforms. Combined, these sources yield a total sediment input of approximately $2.6 \times 10^{6} \mathrm{~m}^{3} \mathrm{a}^{-1}$. Given the many assumptions behind these estimates, this input value is comparable to the accumulation value of $2.0 \times 10^{6} \mathrm{~m}^{3} \mathrm{a}^{-1}$ based on subtidal accumulation of $0.5 \times 10^{6}$ $\mathrm{m}^{3} \mathrm{a}^{-1}$ (Amos and Joice 1977) and intertidal accumulation estimates of $1.5 \mathrm{x} 10^{6} \mathrm{~m}^{3} \mathrm{a}^{-}$ ${ }^{1}$ (Shaw et al. 2012). This relative balance suggests that the Minas Basin acts as a sediment trap, and sediment is not being exported out of the system.

Grain size distributions support the hypothesis that the Minas Basin is acting as a sediment trap. Grain sizes along the coastline and in the subtidal nearshore and deep water deposits are similar (Table 3). Furthermore, sediments coarsen from onshore to offshore. Fine sand dominates cliffs and till, fine and medium sand is seen in beach samples, and medium and coarse sand dominates the nearshore and deep water sites respectively (Figure 6b). This pattern is typical of tidally dominated systems where the finest sediments are winnowed transported and deposited into salt marsh regions where currents are weakest (Allen, 2000). This evidence supports the hypothesis (Gelati 2012; Hill and Gelati accepted) that the disagreement between observed and mean grain size and maximum tidal bed shear stress in the Minas Basin is caused by a inputs of sediment that are finer than 
expected based on the large hydrodynamic stresses.

Models (Li et al. 2015; Wu et al. 2011; Wu et al. 2016) and observations (Amos and Long 1980) indicate that sediment transport through the Minas Channel represents a net source of sediment to the Minas Basin. Previously constructed sediment budgets, however (Amos and Joice 1977; Amos and Long 1980; Shaw et al. 2012) made this impossible, because cliff erosion delivered more sediment to the Minas Basin than was stored in subtidal and intertidal deposits. The lower volumetric inputs from coastal erosion measured in this study create a sediment budget for the Minas Basin for which sediment influx through the Minas Channel can be accommodated.

Amos and Joice (1977) used estimates of inputs to the Minas Basin to speculate that its volume is decreasing, despite rising sea levels. They proposed net inputs from coastal erosion, influx through the Minas Channel and rivers $\left(5.0 \times 10^{6}\right.$ $\mathrm{m}^{3} \mathrm{a}^{-1}$ ). Sea level rise of $3 \mathrm{~mm} \mathrm{a}^{-1}$ increases volume of the Minas Basin by $3.3 \times 10^{6}$ $\mathrm{m}^{3} \mathrm{a}^{-1}$, and coastal retreat adds and additional $1.3 \times 10^{5} \mathrm{~m}^{3} \mathrm{a}^{-1}$, for a total of $3.4 \times 10^{6}$ $\mathrm{m}^{3} \mathrm{a}^{-1}$. This budget (Amos and Joice 1977) indicates that the Minas Basin is decreasing in volume by $1.6 \times 10^{6} \mathrm{~m}^{3} \mathrm{a}^{-1}$. The updated budget provided here leads to the opposite conclusion. With net inputs of $2.6 \times 10^{6} \mathrm{~m}^{3} \mathrm{a}^{-1}$, and the volume increase proposed by Amos and Joice (1977), the volume of the Basin is increasing by $0.8 \mathrm{x}$ $10^{6} \mathrm{~m}^{3} \mathrm{a}^{-1}$ 
When a system is not in hydrodynamic equilibrium with bottom currents, simple conclusions between changes in current speed and changes in sediment texture cannot be drawn. Accurate models of sediment texture require coupled hydrodynamic and sediment models in which sediment sources are spatially and temporally resolved. If, however, sediment bed texture is dominated by inputs and not by bottom current speeds, and if inputs are not likely to be affected substantially by anticipated changes to the environment, then a model of sediment texture, arguably, is not necessary, because texture is unlikely to change. Sediment inputs to the Minas Basin by coastline erosion and excavation of the seabed are unlikely to be altered dramatically by tidal power extraction, so seabed texture is not likely to be affected either (Hill and Gelati accepted).

\section{CONCLUSIONS}

Over the past 50 years sediment from coastal erosion entered the Minas Basin at a rate of $1.1 \times 10^{6} \mathrm{~m}^{3} \mathrm{a}^{-1}$. Most of this input was from cliff erosion along the north shore of the Central Minas Basin where coastline elevations and erosion rates were both high. This updated value is smaller than previously estimated inputs. With this new estimate, sediment input rates are comparable to sediment accumulation rates within the Basin, showing that the Minas Basin acts as a sediment trap. Grain size distributions show coarsening from onshore to offshore, which is consistent with a tidally dominated system and also support this hypothesis. 
Updated measurements of sediment input to the Minas Basin provided by this study support the findings by Hill and Gelati (accepted) that bottom sediment texture in the Minas Basin is not in hydrodynamic equilibrium with tidal bed shear stress. Simple correlations, therefore, do not exist between changes in current speeds and changes in sediment texture within this system. Sediment input from coastal erosion needs to be included in future sediment dynamic and texture models in order for them to describe accurately how sediment texture is likely to respond to changes in hydrodynamic stress. If sediment texture is dominated by inputs from cliff sources and not by bottom currents, then a logical corollary, is that changes in current speeds due to tidal power extraction likely will have little impact on the overall sediment texture in the Minas Basin.

\section{ACKNOWLEDGEMENTS}

We would like to acknowledge NSERC for funding support and Cintia Fernandes for help with sample collection and analysis.

\section{LITERATURE CITED}

Allen, J.R.L., 2000. Morphodynamics of Holocene salt marshes: a review sketch from the Atlantic and Southern North Sea coasts of Europe. Quaternary Science Reviews, 19(12): 1155 - 1231.

Ashton, A.D., Walkden, M.J.A., and Dickson, M.E., 2011. Equilibrium responses of cliffed coasts to changes in the rate of sea level rise. Marine Geology, 284: $217-229$. 
Amos, C. L., 1978. The postglacial evolution of the Minas Basin, N. S.; A sedimentological perspective. Journal of Sedimentary Petrology, 48: 965982.

Amos, C.L., and Joice, G.H.E., 1977. The sediment budget of the Minas Basin, Bay of Fundy, N.S., Data Series/B1-D-77-3, Geological Survery of Canada, 411 pp.

Amos, C.L., and Long, B.F.N., 1980. The sedimentary character of the Minas Basin, Bay of Fundy. In: McCann, S.B. (ed.), The Coastline of Canada. Geological Survey of Canada. 123-152.

Bird, E., 1969. Coasts, Science, 166.

Brooks, S.M., and Spencer, T., 2012. Shoreline retreat and sediment release in response to accelerating sea level rise: Measuring and modelling cliffline dynamics on the Suffolk Coast, UK. Global and Planetary Change, 80 - 81: 165 $-179$.

Buffington, J., and Montgomery, D., 1999. Effect of sediment supply on surface textures of gravel-bed rivers, Water Resources Research. 35: 3523 - 3530.

Desplanque, C., and Mossman, D., 2004. Tides and their seminal impact on the geology, geography, history and socio-economics of the Bay of Fundy, eastern Canada, Atlantic Geology, 40: 1 - 130.

Dunn, S.; Friedman, R., and Baish, S., 2000. Coastal erosion: evaluating the risk. Environment: Science and Policy for Sustainable Development, 42(7): 36 - 45.

Emery, K., and Kuhn, G., 1982. Sea cliffs: their processes, profiles and classification. Geological Society of America Bulletin, 93: 644 - 654. 
ESRI ${ }^{\circledR}$ White Paper., 2001. ArcGIS Spatial Analyst: advanced GIS spatial analysis using raster and vector data. Redlands, CA.

Folk, R.L., and Ward, W.C., 1957. Brazos River bar, a study in the significance of grain size parameters. Journal of Sedimentary Petrology, 27.

Garrett, C., 1972. Tidal resonance in the Bay of Fundy and Gulf of Maine. Nature, 238: 441-443.

Gelati, S., 2012. Modelling the impact on sediment texture of large-scale tidal power in the Bay of Fundy. M.Sc. thesis, Dalhousie University, Halifax, N.S.

George, D. A., Hill, P. S., and Milligan, T. G., 2007. Flocculation, heavy metals (Cu, Pb, Zn) and the sand-mud transition on the Adriatic continental shelf, Italy. Continental Shelf Research, 27: 475-488.

George, D.A., and Hill, P.S., 2008. Wave Climate, sediment supply and the depth of the sand-mud transition: a global survey. Marine Geology, 254(3): 121 - 128. Hasegawa, D.; Sheng, J.; Greenberg, D.A., and Thompson, K.R., 2011. Far-field effects of tidal energy extraction in the Minas Passage on tidal circulation in the Bay of Fundy and Gulf of Maine using a nested-grid coastal circulation model. Ocean Dynamics, 61(11): 1845-1868.

Hill, P.S., and Gelati, S., accepted, 2016. Competent versus observed grain size on the sea bed of the Bay of Fundy and Gulf of Maine. Journal of Coastal Research. Knight, R.J., 1972. Cobequid Bay sedimentology project: a progress report. Martime Sedimentology, 8: $301-340$. 
Law, B.A.; Hill, P.S.; Milligan, T.G.; Curran, K.J.; Wiberg, P.L., and Wheatcroft, R.A., 2008. Size sorting of fine-grained sediments during erosion: Results from the western Gulf of Lions. Continental Shelf Research, 28: 1935 - 1946.

Lee, E.M., 2008. Coastal cliff behavior: observations on relationship between beach levels and recession rates. Geomorphology 101: 588 - 571.

Li, M.; Shaw, J.; Todd, B.; Kostylev, V., and Wu, Y., 2013. Sediment transport and development of banner banks and sandwaves in an extreme tidal system: Upper Bay of Fundy, Canada. Continental Shelf Research, 83: 86 - 107.

Li, M.; Hannah, C.; Perrie, W.; Tang, C.; Prescott, R., and Greenberg, D., 2015.

Modelling seabed shear stress, sediment mobility and sediment transport in the Bay of Fundy. Canadian Journal of Earth Science, 52: 757-775.

Parker, M., Westhead, M., and Service, A., 2007. Ecosystem overview report for the Minas Basin Nova Scotia, Prepared for Ocean and Habitat Branch Maritimes Region, Fisheries and Oceans Canada.

Porter, N.J., Trenhaile, A.S., Prestanski, K.J., and Kanyaya, J.I., 2010. Shore platform downwearing in eastern Canada: The mega-tidal Bay of Fundy. Geomorphology, 118: 1-12.

Pye, K., and Blott, S., 2015. Spatial and temporal variations in soft cliff erosion along the Holderness coast, East Riding of Yorkshire, UK. Journal of Coastal Conservation, 19: $785-808$.

Robinson, L., 1977. Marine erosive processes at the cliff foot, Marine Geology, 23: $257-271$. 
Schwinghamer, P.; Guigné, J.Y., and Siu, W.C., 1996. Quantifying the impact of trawling on benthic habitat structure using high resolution acoustics and chaos theory. Canadian Journal of Fisheries and Aquatic Sciences, 53: 288 296.

Shaw, J.; Todd, B.P.; Li, M.Z., and Wu, Y., 2012. Anatomy of the tidal scour system at Minas Passage, Bay of Fundy, Canada. Marine Geology, 323-325.

Trenhaile, A.S., 1999. The Width of Shore Platforms in Britain, Canada, and Japan. Journal of Coastal Research, 15(2): 355 - 364.

Wu, Y.; Chaffey, J.; Greenberg, D.A.; Colbo, K., and Smith, P.C., 2011. Tidally-induced sediment transport patterns in the upper Bay of Fundy: A numerical study. Continental Shelf Research, 31(19-20): 2041-2053.

Wu, Y.; Chaffey, J.; Greenberg, D.A., and Smith, P.C., 2016. Environmental impacts caused by tidal power extraction in the upper Bay of Fundy. AtmosphereOcean, 54(3): 326-336.

Young A. R., Guza R., Flick, R., O’Reilly, W., and Gutierrez, R. 2009. Rain, waves and short term evolution of composite sea cliffs in Southern California. Marine Geology, 267: $1-7$. 
List of Figure Captions:

Figure 1. Map of the Minas Basin study area showing locations of land and seabed sediment samples. Coloured lines with corresponding numbers 1-6 indicate sections used for coastline retreat and sediment input analysis.

Figure 2. Rates of coastline retreat around the Minas Basin based on aerial photographs from 1964 - 2013. Numbers 1 - 6 indicate study sections.

Figure 3. Illustration of the changes in linear retreat rates along the Minas Basin coastline from time period 1 (1964 - Early 1990s) and time period 2 (Early 1990s to 2013). Numbers 1 - 6 indicate study sections.

Figure 4. Rates of volumetric sediment input from coastal retreat around the Minas Basin based on aerial photographs from 1964 - 2013 and elevation data. Numbers 1 -6 indicate study sections.

Figure 5. Illustration of the changes in sediment input rates along the Minas Basin coastline from time period 1 (1964 - Early 1990s) and time period 2 (Early 1990s to 2013). Numbers 1 - 6 indicate study sections.

Figure 6. a) Average percent distribution of gravel, sand, and silt and clay sized 
particles and b) Average percent distribution of coarse, medium, fine and very fine sand for till (T) $(n=7)$, cliff (C) $(n=56)$, beach (B) $(n=29)$, nearshore (NS) $(n=92)$, and deep water (DW) (n=69) sediment samples.

Table 1. Dates of aerial photographs and satellite imagery used for each section.

Table 2. Textural class names of grain sizes (Folk and Ward 1957).

Table 3. Mean size and sorting of land $(n=92)$ and seabed $(n=161)$ samples based on Folk and Ward (1975) classification system. 




Figure 1. Map of the Minas Basin study area showing locations of land and seabed sediment samples. Coloured lines with corresponding numbers 1-6 indicate sections used for coastline retreat and sediment input analysis.

$252 \times 154 \mathrm{~mm}(72 \times 72 \mathrm{DPI})$ 


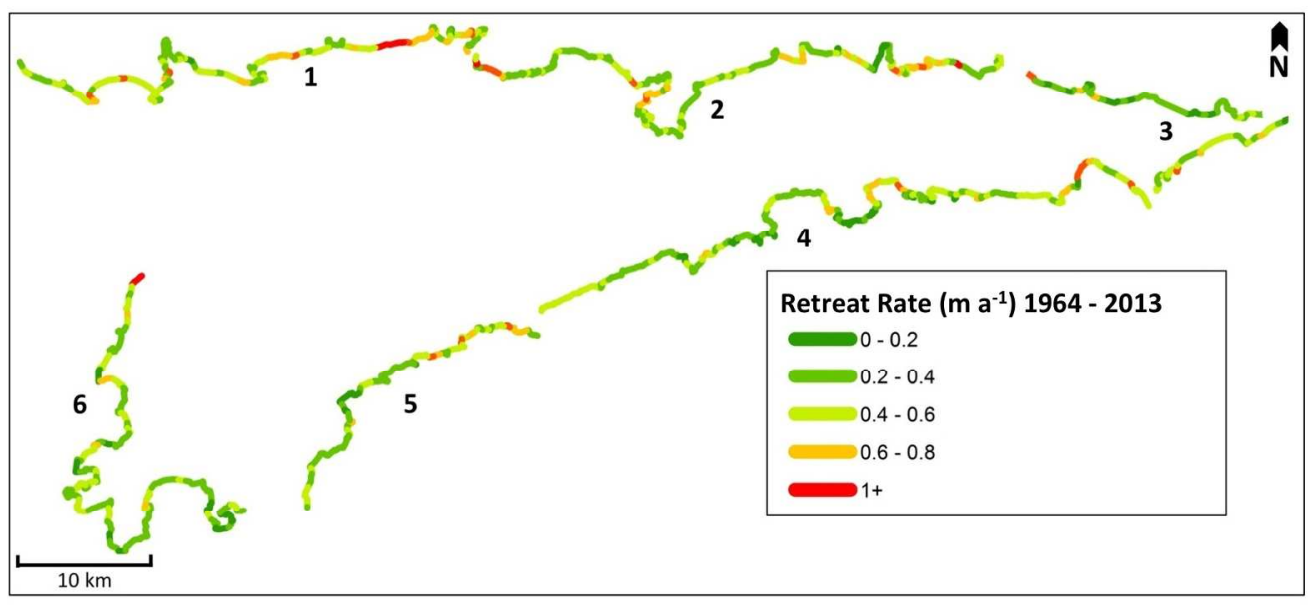

Figure 2. Rates of coastline retreat around the Minas Basin based on aerial photographs from $1964-2013$. Numbers $1-6$ indicate study sections.

$793 \times 595 \mathrm{~mm}(72 \times 72$ DPI $)$ 


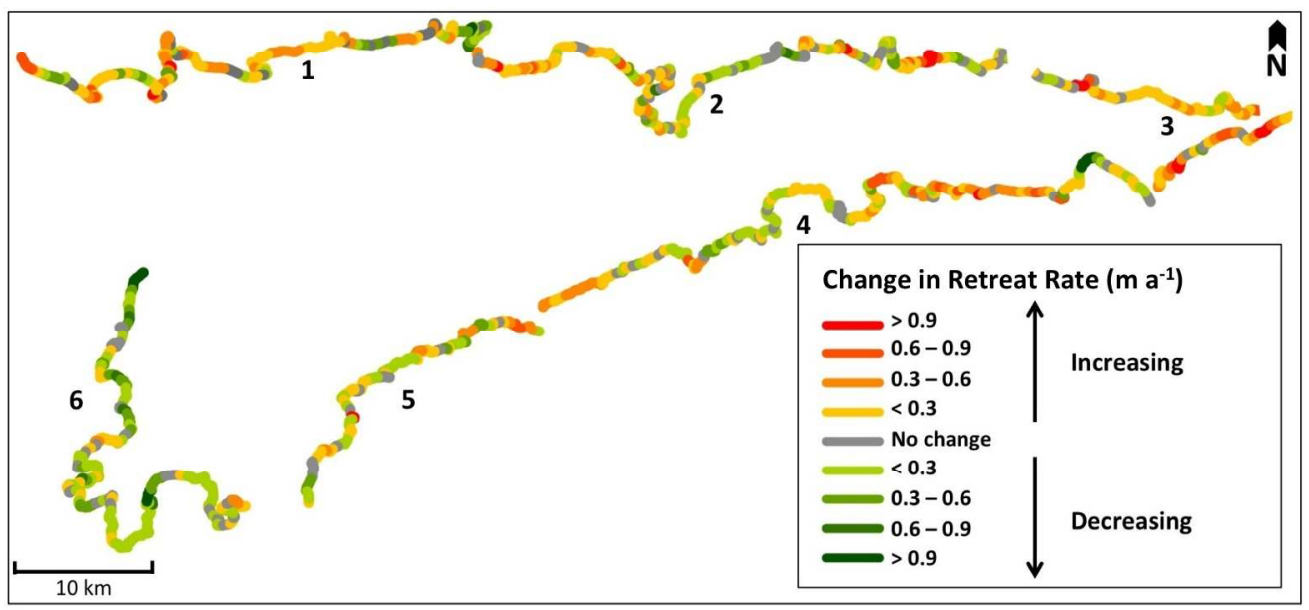

Figure 3. Illustration of the changes in linear retreat rates along the Minas Basin coastline from time period 1 (1964 - Early 1990s) and time period 2 (Early 1990s to 2013). Numbers 1 - 6 indicate study sections.

$$
793 \times 595 \mathrm{~mm}(72 \times 72 \text { DPI })
$$




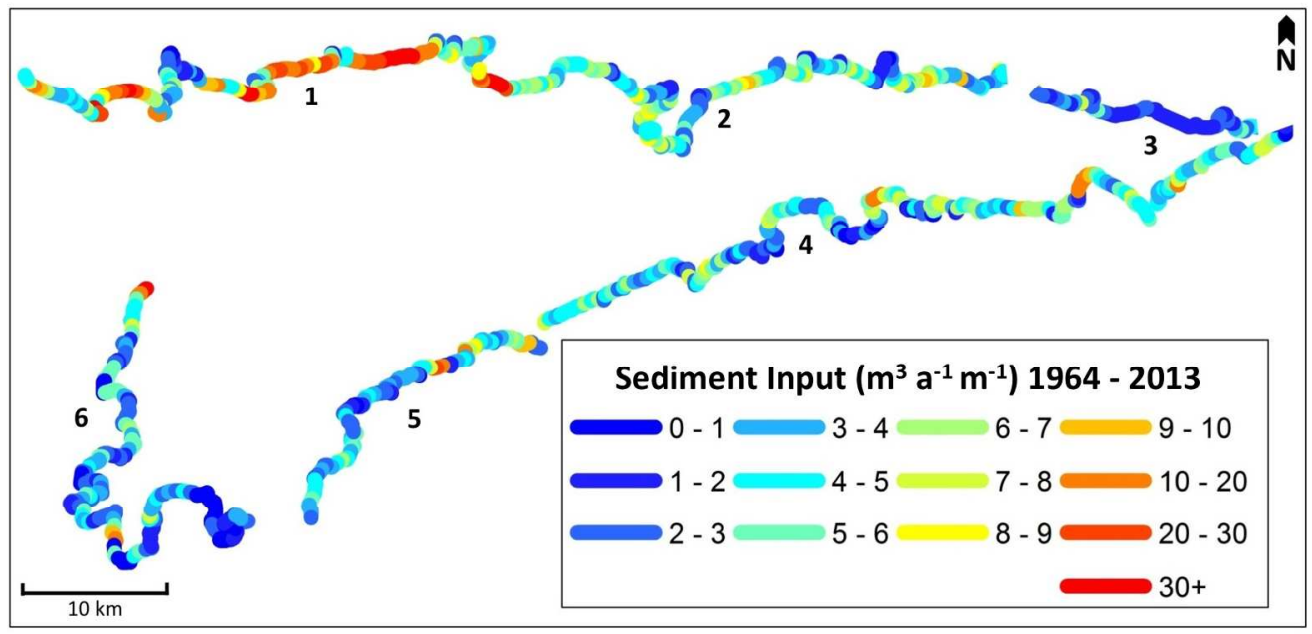

Figure 4. Rates of volumetric sediment input from coastal retreat around the Minas Basin based on aerial photographs from 1964 - 2013 and elevation data. Numbers $1-6$ indicate study sections.

$793 \times 595 \mathrm{~mm}(72 \times 72$ DPI $)$ 


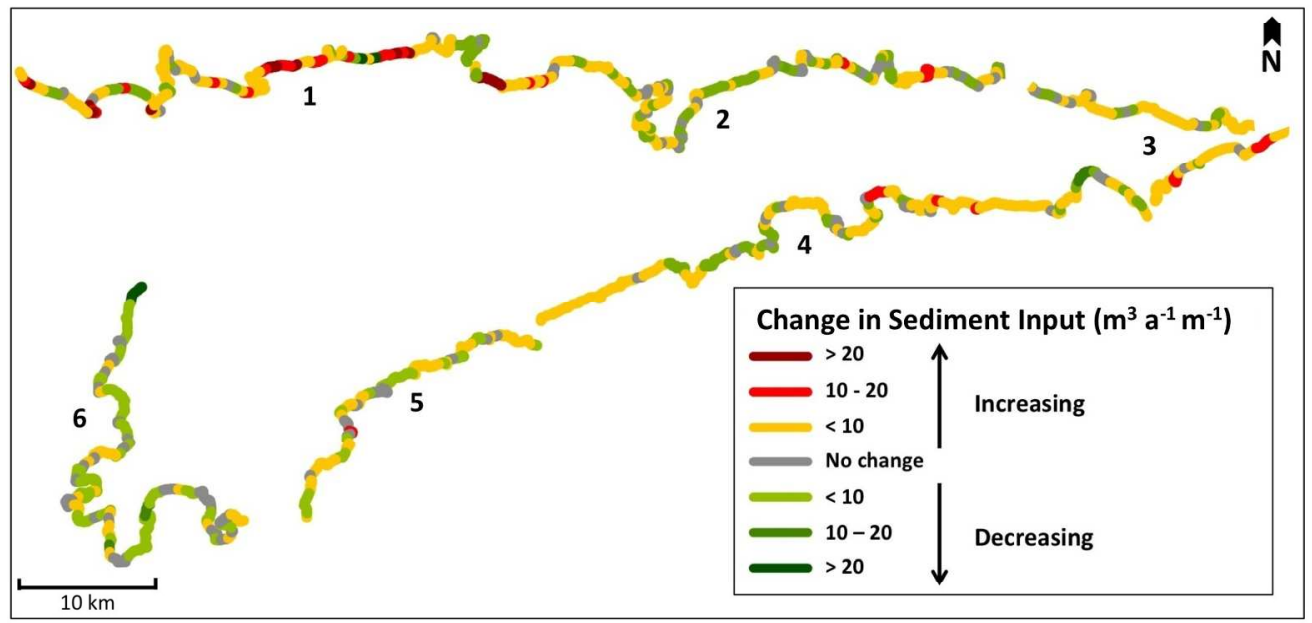

Figure 5. Illustration of the changes in sediment input rates along the Minas Basin coastline from time period 1 (1964 - Early 1990s) and time period 2 (Early 1990s to 2013). Numbers 1 - 6 indicate study sections.

$793 \times 595 \mathrm{~mm}(72 \times 72$ DPI $)$ 


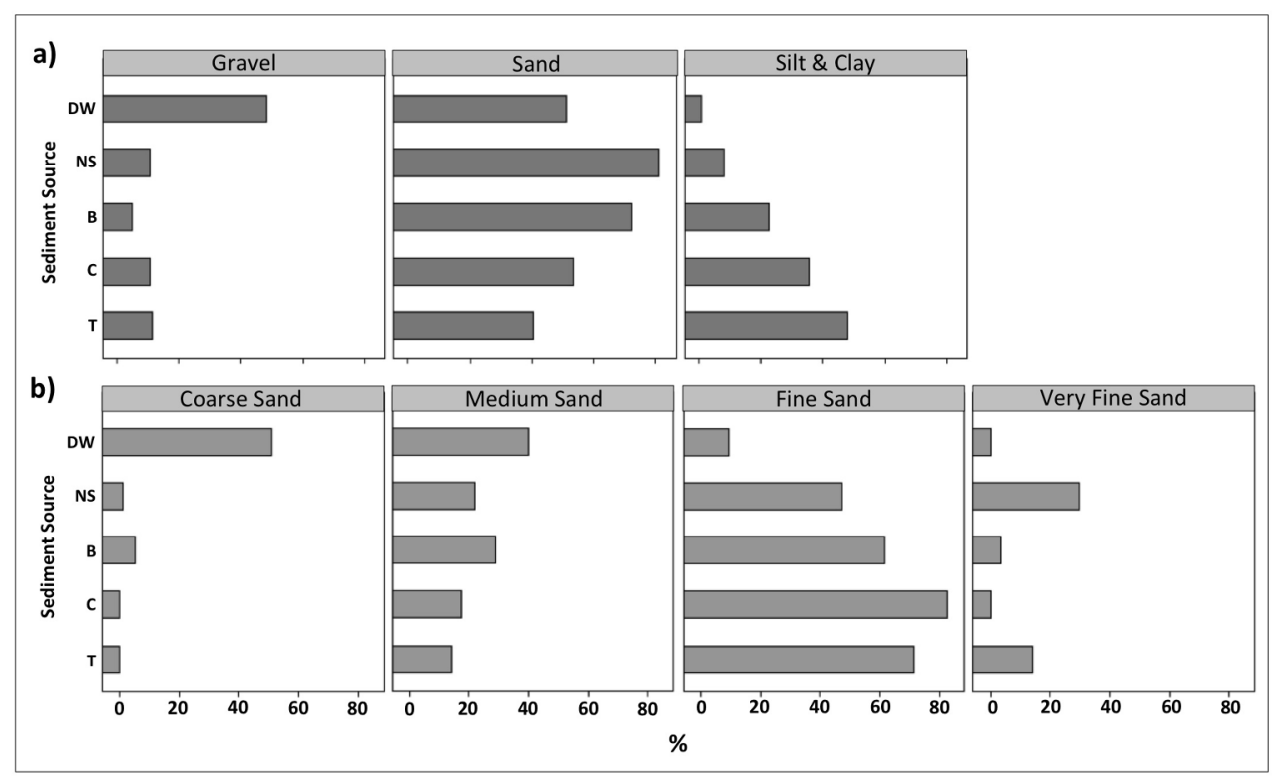

Figure 6. a) Average percent distribution of gravel, sand, and silt and clay sized particles and b) Average percent distribution of coarse, medium, fine and very fine sand for till $(T)(n=7)$, cliff $(C)(n=56)$, beach $(B)$ $(n=29)$, nearshore (NS) $(n=92)$, and deep water (DW) $(n=69)$ sediment samples. 


\begin{tabular}{|c|c|c|}
\hline Section & Aerial Photos & Satellite Imagery \\
\hline 1 & 1964,1995 & 2013 \\
\hline 2 & 1964,1994 & 2013 \\
\hline 3 & 1964,1994 & 2013 \\
\hline 4 & 1964,1992 & 2013 \\
\hline 5 & 1964,1992 & 2013 \\
\hline 6 & 1977,1992 & 2013 \\
\hline
\end{tabular}




\begin{tabular}{ccc}
\hline Texture & Size $(\boldsymbol{\phi})$ & Metric Size $(\boldsymbol{\mu})$ \\
\hline Gravel & $<-1$ & $>2000$ \\
Very coarse sand & -1 to 0 & 2000 to 1000 \\
Coarse sand & 0 to 1 & 1000 to 500 \\
Medium sand & 1 to 2 & 500 to 250 \\
Fine sand & 2 to 3 & 250 to 125 \\
Very fine sand & 3 to 4 & 125 to 63 \\
Silt and Clay & $>4$ & $<63$ \\
\hline
\end{tabular}




\section{LAND SAMPLES}

\begin{tabular}{llll}
\hline $\begin{array}{l}\text { Average size }(\phi) \\
2.25\end{array}$ & $\begin{array}{l}\text { Average size (verbal) } \\
\text { Fine sand }\end{array}$ & $\begin{array}{l}\text { Standard deviation } \\
0.807\end{array}$ & $\begin{array}{l}\text { Sorting } \\
\text { Moderately Sorted }\end{array}$ \\
\hline \multicolumn{3}{r}{ SEABED SAMPLES } \\
\hline Average size $(\boldsymbol{\phi})$ & $\begin{array}{l}\text { Average size (verbal) } \\
2.14\end{array}$ & Standard deviation & Sorting \\
& Medium sand & 0.756 & Moderately Sorted \\
\hline
\end{tabular}

